\title{
Is radio an effective method for delivering actionable information for responding to emerging pest threats? A case study of fall armyworm campaign in Zambia
}

Harrison Rware ${ }^{1 *}(0)$, Monica K. Kansiime ${ }^{1}$, Idah Mugambi ${ }^{1}$, David Onyango ${ }^{1}$, Justice A. Tambo², Catherine Mloza Banda ${ }^{3}$, Noah A. Phiri ${ }^{3}$, Gilson Chipabika ${ }^{4}$, Mathews Matimelo ${ }^{4}$, Dorcas Kabuya Chaaba ${ }^{5}$, Tamsin Davis ${ }^{6}$ and Julien Godwin ${ }^{7}$

\begin{abstract}
Background: The Fall Army Worm (FAW) radio campaign was implemented between November 2018 and April 2019 in key maize growing areas and locations with reported high severity of fall armyworm as identified by national stakeholders. We evaluated the effectiveness of radio mass extension campaign in achieving scale, and effect on farmers' knowledge and uptake of management practices for fall armyworm (FAW). We also assessed the factors determining farmers' participation in radio campaign, to inform future and similar campaigns.

Methods: Data were gathered through a household survey targeting locations where the campaign was implemented; and 250 male and 215 female farmers were surveyed. The study was conducted in four of the seven provinces where the campaign took place-Eastern, Luapula, Copperbelt and Southern provinces. Selection of the sample provinces was based on reported rainfall distribution during the season and severity of FAW infestation, radio coverage areas and maize growing intensities.

Results: The radio campaign reached an estimated 1.4 million farmers. Survey results show that both male and female radio listeners were significantly more aware of fall armyworm, and more likely to adopt management practices than non-radio listeners, in particular preventive measures such as frequent monitoring, intercropping and crop rotation. This means that participation in the radio-based extension campaign significantly increased farmers' knowledge and stimulated uptake of management practices for FAW. However, the survey showed that only $49 \%$ of the respondents listened to at least one FAW radio episode. Predictors of farmer participation in radio campaign were; gender, education level, and maize farm size.
\end{abstract}

Conclusions: The results imply that deliberate promotion of such programs would enhance listenership and improve interactivity while at the same time integrating other extension approaches. The integration also provides opportunities for equally reaching women as men, given the observed digital divide.

Keywords: Agricultural Information, Smallholder farmers, Fall armyworm, Zambia

*Correspondence: h.rware@cabi.org

' CABI, Canary Bird, 673 Limuru Road, Muthaiga, P.O. Box 633-00621, Nairobi, Kenya

Full list of author information is available at the end of the article

\section{Background}

The invasive pest, fall armyworm (FAW) (Spodoptera frugiperda J.E. Smith), first presence in Africa was confirmed in 2016 (Rwomushana et al. 2018). Research appropriate credit to the original author(s) and the source, provide a link to the Creative Commons licence, and indicate if changes were made. The images or other third party material in this article are included in the article's Creative Commons licence, unless indicated otherwise in a credit line to the material. If material is not included in the article's Creative Commons licence and your intended use is not permitted by statutory regulation or exceeds the permitted use, you will need to obtain permission directly from the copyright holder. To view a copy of this licence, visit http://creativecommons.org/licenses/by/4.0/. The Creative Commons Public Domain Dedication waiver (http://creativecommons.org/publicdomain/zero/1.0/) applies to the data made available in this article, unless otherwise stated in a credit line to the data. 
studies estimated that maize crop losses in Africa due to fall armyworm would range between 8.3 and 20.6 million tonnes per year if management measures were not put in place (Rwomushana et al. 2018, Pratt 2017). In Zambia, the value of the 2018 annual maize crop lost due to fall armyworm was estimated at US\$159million (Rwomushana et al. 2018, Pratt et al. 2017). A majority of maize farmers in Africa are smallholders who on average farm 1-2 ha. The farmers have limited access to crop pest information due to limited extension services in Africa and for them to sustainably produce maize, they need significant support to sustainably manage FAW in their cropping systems (FAO 2018, IAPRI 2016).

Invasive pests pose new challenges to farming systems, as extension workers and farmers often lack information on effective management approaches. The high mobility and quick spread of invasive pests requires wide scale information delivery to contain the problem. Current public extension services are constrained by limited capacity and resourcing. One of the challenges identified by (Emily et al. 2017) for agricultural extension is how to reach remote, rural farmers with information in a form they can understand, apply with relative ease and by so doing reap benefits.

Empirical evidence has shown that radio is the most widely used medium in much of the developing world and close to $75 \%$ of households in developing countries have access to radio (Hudson et al. 2017, Hailu et al. 2017, Kembero 2014, Duncombe 2012) and radio in Zambia is the most accessible and used medium at $68 \%$ compared to $85 \%$ in urban areas (ZICTA 2018, Masuki 2010). Besides, the continent's New Partnership for Africa's Development (NEPAD), has put as part of its priority the need to tap media such as radio and newer information and communication technologies to avail information for sustainable development and response to agricultural challenges (Africa Renewal 2005; Staatz et al. 2008, Chapota 2015, Emmanuel et al. 2013). Previous evaluation of radio effects has shown that participatory radio campaigns implemented by Farm Radio International (FRI) resulted in increased knowledge and adoption beneficial agricultural practices in six African countries (Tambo et al. 2019).

CABI, 2018-through its programme on Action on Invasive-launched FAW-specific activities in Zambia in partnership with the Ministry of Agriculture and Livestock and Zambia Agricultural Research Institute (ZARI) and other partners. The programme supported a radiocampaign targeting smallholder farmers in seven provinces in Zambia with information on FAW identification, monitoring and management. This study assesses the effectiveness of the radio campaign in reaching scale of information reach and influencing knowledge and uptake of management practices for FAW. We also evaluate factors that determine farmer participation in radio-based extension programs to support effective future programming for delivering actionable information on emerging pest threats.

\section{Methodology \\ Fall armyworm radio campaign}

The FAW radio campaign was implemented between November 2018 and April 2019 in key maize growing areas and locations with reported high severity of fall armyworm as identified by national stakeholders. The process of designing and delivering FAW campaign involved multi-stakeholders from Ministry of Agriculture, National Agricultural Research Systems (NARS), farmer organizations, dissemination partners (e.g. radio), and the national fall army worm task force. The process (Fig. 1) involved a formative appraisal to enable selection of appropriate communication channels and timing of information delivery suitable for male and female farmers. This was followed by development of a technical brief. Development of technical briefs was informed by available empirical evidence (such as the FAO and USAID/CIMMYT manuals, Farm Radio Guide), and research information from National Agricultural Research Systems (NARS). Campaign planning and implementation followed, and monitoring and learning undertaken during the period of the campaign.

The campaign messages covered FAW identification, monitoring and management practices. Delivery of messages was timed to the cropping calendar to ensure the received messages were relevant to the current agricultural activities. The radio messages were pre-recorded and translated into all the seven national languages of Zambia, as well as English, and aired on national radio Zambia National Broadcasting Corporation (ZNBC) and six regional radio stations-Breeze FM, Eastern Province; Kasempa FM, North western province; Radio Yangeni, Luapula Province; Sky FM, Southern Province; Liseli FM, Western Province; and Ichengelo radio, Copperbelt Province. Implementing partners for the FAW campaign were Ministry of Agriculture (through the National Agricultural Information Services (NAIS), Zambia Agricultural Research Institute (ZARI), National Union of Smallholder Farmers Association of Zambia (NUSFAZ), Zambia Environmental Management Agency (ZEMA), CropLife, and the University of Zambia, and CABI. The radio campaign was implemented in conjunction with agricultural extension activities.

\section{Study area, population and sample}

The study was conducted in four of the seven provinces where the campaign took place-Eastern, Luapula, 


\section{Formative research}

Enables selection of channels and timing of delivery of messages to ensure wide reach of the target

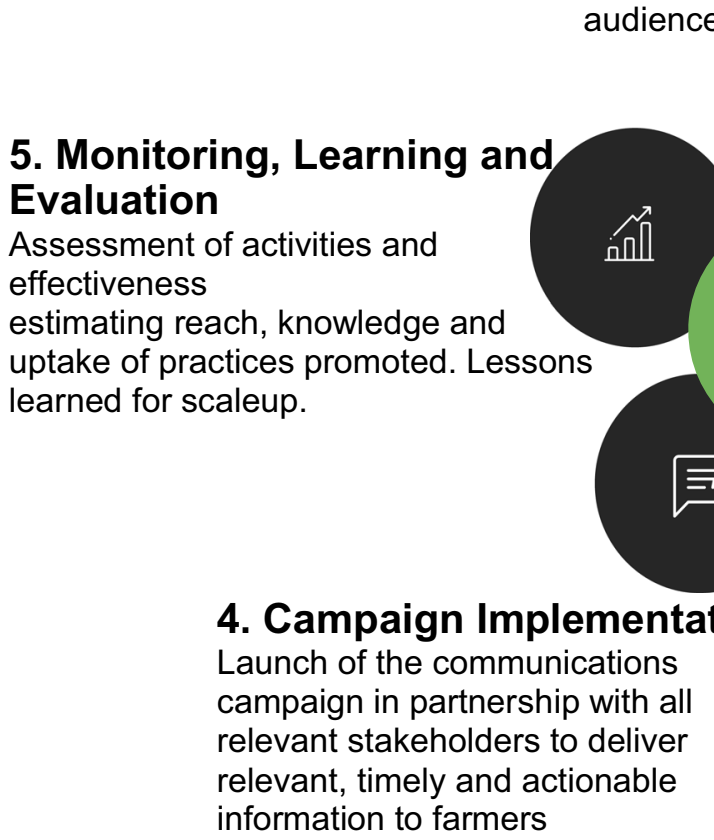

(er)

5. Monitoring
Evaluation

Assessment of activities and effectiveness estimating reach, knowledge and uptake of practices promoted. Lessons learned for scaleup.

\section{Campaign Implementation Launch of the communications information to farmers}

\section{Technical Brief} Development Technical brief forms the basis for design of messages to be disseminated through various channels

\section{Campaign planning}

Brings together all of the above information to record the rationale for the communication campaign. This includes developing appropriate messages and campaign plan aligned to cropping calendar

Fig. 1 campaign implementation plan

Copperbelt and Southern provinces. Selection of the sample provinces was based on reported rainfall distribution during the season and severity of FAW infestation, radio coverage areas and maize growing intensities. The northern part of Zambia enjoyed fairly higher than average rainfall amounts, whilst the southern part experienced quite dry conditions.

The study population comprised of maize growing farmers in the selected provinces. A representative sample of camps was obtained using the government extension criteria, based on whether it is a maize growing area, suffered FAW attacks in the previous season and whether the key radio stations used in the campaign covered these areas. Respondent households were randomly identified following a road network and interviewing one farmer and skipping the next farmer. In instances where the farmer was missed, a repeat was done the next day. Information was gathered from both the radio listeners and non-listeners who were selected based on information from radio coverage areas and a filter question on radio listenership. Moreover, a filter question was included to establish if the household had grown maize in the November 2018-April 2019 growing season, and only those who had grown maize in the referred season were interviewed. A total of 465 farm households (250 male and 215 female) were interviewed across the four provinces.

Data were collected through a structured questionnaire administered by trained enumerators. The questionnaire had components on participation in the FAW campaign; household socio-economic characteristics; maize production details; knowledge of and attitude towards FAW management; adoption of interventions for FAW management; access and proximity to institutional support services; and use of pesticides.

Data collection was done through face to face interviews using the Open Data Kit (ODK) platform deployed on tablet computers. Before the data collection exercise, training was done using both the paper and the online versions of the questionnaire to ensure that the questions and objectives of the study were clearly understood by the enumerators. The questionnaire was pre-tested in Kafue district of central province and corrections done. ODK inbuilt data validation features were used to guarantee data quality. The data were received in near realtime on an aggregate server, quality checks done and feedback provided to the field team leaders. This further ensured quality control at the field level. The base production season was November 2018 to April 2019, thus all data collected referred to this season. Before 
interviews, enumerators obtained verbal consent from the respondents.

\section{Empirical methods}

The purpose of the study was to assess the effect of FAW radio campaign in achieving scale of farmer reach and influence on farmers' knowledge and practices for fall armyworm management. These attributed were compared between campaign participants (listened to radio campaign) and non-participants (those that did not listen to the radio campaign). Three key knowledge questions were assessed; identification, monitoring and management. Farmers were asked a series of questions to assess their knowledge on specific aspects of FAW identification, monitoring, and management. Respondents gave their subjective rating on a 2-point scale; $1=$ agree and $2=$ disagree. The knowledge statements were coded by assigning 1 to correct responses and 0 , otherwise. Using Principal Component Analysis (PCA), indices for the three knowledge categories were developed. In order to estimate the effect of radio participation on the knowledge questions, multiple regression models were estimated with indices for identification, monitoring, and management as the dependent variables. The model was specified as;

$$
y_{i}=\alpha_{i}+\beta x_{i}+\gamma F A W_{i}+\varepsilon_{i}
$$

where $y_{i}$ is an index for the knowledge questions for household $i$, Independent variables included; $F A W_{i}$ and is a vector for participation in the FAW campaign $(1=$ yes, $0=$ otherwise), and $\varepsilon$ is the error term. Other explanatory variables, $x$ were included in the model; socio-demographic characteristics (sex of respondent, age category, education level, household size, farm size), and location of respondent $i$.
We further estimated the factors that determine a farmer's participation in a radio campaign, to guide design of future campaign programs. Probit regression model was estimated. The probit model assumes that while we only observe the values of 0 and 1 for the variable $Y$, there is a latent, unobserved continuous variable $Y$ ' that determines the value of $Y$. Thus, for this study we assume that participation in radio campaign $\left(Y^{\prime}\right)$ can be specified as follows:

$$
Y_{i}^{\prime}=\Delta_{i}+\beta x_{i}+u_{i}
$$

And that:

$$
\begin{aligned}
& Y_{i}=1, \text { if } Y^{\prime}>0 \\
& Y_{i}=0, \text { otherwise. }
\end{aligned}
$$

Where $x_{i}$ is a set of explanatory variables for respondent $i, \beta$ represent a vector of unknown parameters, and $u$ represent a random disturbance term.

\section{Data analysis}

Data analysis was done using Stata 15 statistical package. Pearson $\mathrm{X}^{2}$, Principle component analysis, multiple regression models and t-test were used to test significance of proportions and means across the campaign participants and non-participants.

\section{Results and discussion} Respondent characteristics

Table 1 shows respondent characteristics. On average, the household size was 7 persons. A majority of the respondents (48\%) had attained secondary level of education, $42 \%$ primary level, and $5 \%$ had no formal education

\begin{tabular}{|c|c|c|c|c|c|}
\hline Characteristics & Total sample & Non listeners & Radio listeners & Female & Male \\
\hline HH members (\#) & $7.0(0.1)$ & $6.7(0.3)$ & $7.1(0.2)$ & $6.9(0.2)$ & $7.1(0.2)$ \\
\hline HH members full time on farm (\#) & $4.4(0.1)$ & $4.3(0.2)$ & $4.4(0.1)$ & $4.3(0.2)$ & $4.5(0.1)$ \\
\hline Age of HH head (years) & $52.2(0.6)$ & $50.7(1.2)$ & $52.9(0.8)$ & $51.1(0.9)$ & $53.2(0.9)$ \\
\hline Total farmed land (acres) & $6.3(0.4)$ & $5.7(0.8)$ & $6.6(0.5)$ & $5.4(0.5)$ & $7.1(0.6)$ \\
\hline \multicolumn{6}{|l|}{ Education level (\%) } \\
\hline None & 5 & 3 & 10 & 6 & 5 \\
\hline Primary school & 42 & 41 & 47 & 49 & 36 \\
\hline Secondary school & 48 & 51 & 42 & 40 & 56 \\
\hline University & 3 & 3 & 1 & 4 & 2 \\
\hline Vocational & 2 & 2 & 0 & 2 & 1 \\
\hline Suffered FAW last season & 349 & 88 & 86 & 88 & 87 \\
\hline
\end{tabular}
which is below the national literacy level average of $53 \%$. A majority of farmers (86\%) who participated in the FAW

Table 1 Household characteristics

$\mathrm{HH}$ : household

*Std error in parenthesis 
campaign had experienced FAW on their farms during the November 2018-April 2019 cropping season, compared to $88 \%$ of the non-campaign participants.

On average, male farmers had more land for all activities compared to female farmers ( 7 acres compared to 5 ). Radio campaign participants (who are we refer as radio listeners) had more land for all activities (6.6 acres) compared to non-listeners (5.7 acres). Both household head and spouse worked most of the time on their farms. This was confirmed by the study where most of the household heads $(92 \%)$ work on the farm full time and $6 \%$ part-time while $95 \%$ of the spouses of the household head worked full time on the farm while $4 \%$ work part-time. The average age of the household head was 51 years for the female heads and 53 years for the male heads.

\section{Farmer participation in radio campaign on FAW}

Farmer reach with radio messages was estimated based on radio coverage and signal strength, total potential adult population, total potential rural population, as well as proportion of maize growers. This approach has been used before for example Farm Radio International (Hudson et al. 2017, Wanyama et al. 2015), to map audience coverage and reach. In our analysis, we include a factor of proportion of respondents in the broadcast areas who listened to at least one radio episode on FAW during the campaign season, to estimate actual reach. Figure 2 shows mapping of radio reach in Zambia based on signal strength and population within the radio coverage that were used for computation of reach figures for the radio campaign. Where tower data were not available, for example Radio Yangeni and Sky FM, the broadcasters were asked to provide an estimate of their listenership based on their experience and research. The adult population in Zambia is 52\% according the national bureau of statistics, and from our survey, $49 \%$ of the respondents listened to at least one episode of the FAW campaign during the 2018/19 cropping season. Table 2, shows the estimation of reach based on the statistics estimates, a total of $1.4 \mathrm{~m}$ people were reached with fall armyworm messages via radio. While it is not possible to disaggregate public service message and radio viewership/listenership by gender and age, it is estimated that about $40 \%$

Table 2 Estimated farmer reach with fall armyworm radio messages in Zambia

\begin{tabular}{ll}
\hline Variable & Number \\
\hline Rural population in radio coverage & $5,602,825$ \\
People who listened to radio campaign (49\%) & $2,745,384$ \\
Less population below 14 years (48\%) & $1,427,600$ \\
Estimated reach—Radio & $1,427,600$ \\
Female (40\%) & 542,488 \\
Male (60\%) & 885,112 \\
\hline
\end{tabular}

Seven radio stations were used, some urban and others rural. For urban-based radio stations, their estimated rural listenership was $55.9 \%$, and proportion of the population growing maize was $98 \%$, which were also factored into the final computation of reach. See Additional files 1,2

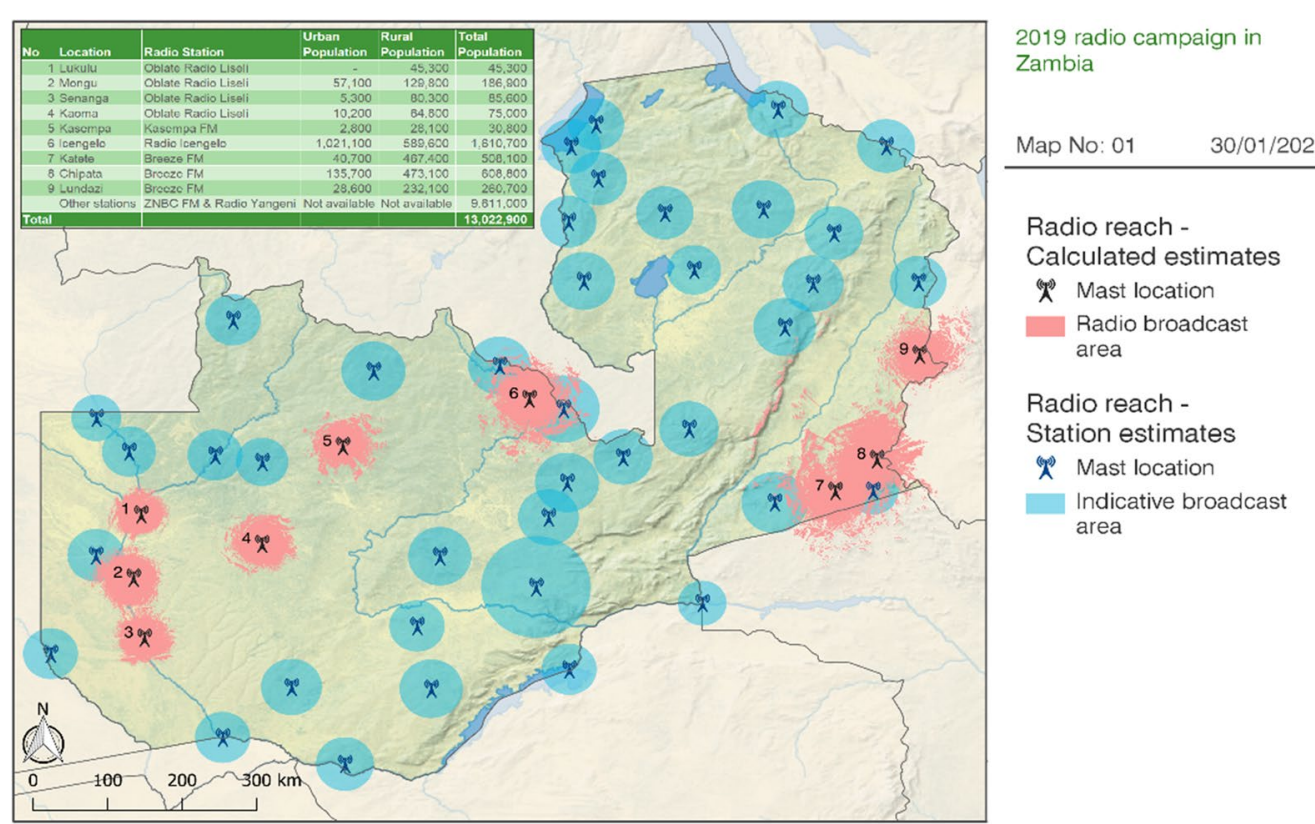

Fig. 2 Radio signal coverage for Breeze FM, Icengelo FM, Kasempa FM, and Liseli FM in Zambia and population reached based on radio signal strength. Map curtesy: T. Beale (CABI) 
of the population reached were women and that $48 \%$ were under 35 years of age. The estimate does not include secondary reach e.g. information sharing within the family, farmer groups or social clubs, which is common in rural setting. Figure 3, shows a comparing of the FM radio mostly listened to and where the FAW message was received from, by the listener categories, where $\mathrm{ZNBC}$ Radio 1, is the most listened followed by ZNBC Radio 2 but this differed by province where Icengelo is listened more in Copperbelt.

Probit regression model was used to assess factors affecting farmer participation in radio campaign. The dependent variable took the form of 1 , if farmer listened to at least one radio episode on fall armyworm and 0 , otherwise. Table 3 shows results of the logit model. Data showed that gender of respondent and land under maize cultivation had positive and significant effects on farmer participation in the radio campaign. Gender of respondent was significant $(P>0.05)$ in influencing farmers decision to take part in the of radio campaign. Relative to the base province, Luampula had a positive and significant influence to the radio listening at $5 \%$ level. This may be attributable to the number of FM radio stations covering the province. On the other hand, compared to the base age of above 60 years, the age between 36 and 60 and those 35 years and below, had a positive and a significant influence on farmers participation in FAW radio campaign at $5 \%$ level of significance, (Table 3). Education levels relative to the base level had no influence on participation on the radio campaign by farmers except the primary education that was shown to positively influence participation at $10 \%$ level of significance. It therefore implies that, gender has a positive influence on radio listening in Zambia and while developing and intervention on this nature, gender ought to be considered.

\section{Farmer knowledge of fall armyworm}

Table 4 shows results of the knowledge questions-identification, monitoring and management. Overall, farmers responded correctly to most of the FAW knowledge questions, but farmers who listened to radio had higher knowledge scores generally compared to those that did not. On FAW awareness, data showed a significant difference $(\mathrm{P}<0.05)$ between radio listeners and non-listeners. More radio listeners (86\%) than non-listeners $(80 \%)$ agreed that FAW can cause $100 \%$ damage and loss on maize and that the signs of FAW damage include small pinholes. Conversely, more non-listeners (45\%) than listeners (36\%) agreed that FAW is spread through infested seeds respectively significant at $10 \%$ level. There was however no significant difference between the proportions of listeners and non-listeners that said FAW only attacks maize.

The results show a significant difference in knowledge on FAW management, between the two groups $(\mathrm{p}<0.01)$, with $88 \%$ of the listeners and $76 \%$ of non-listeners agreeing that early planting at the onset of rains can help reduce FAW incidence. Further, $68 \%$ of listeners and

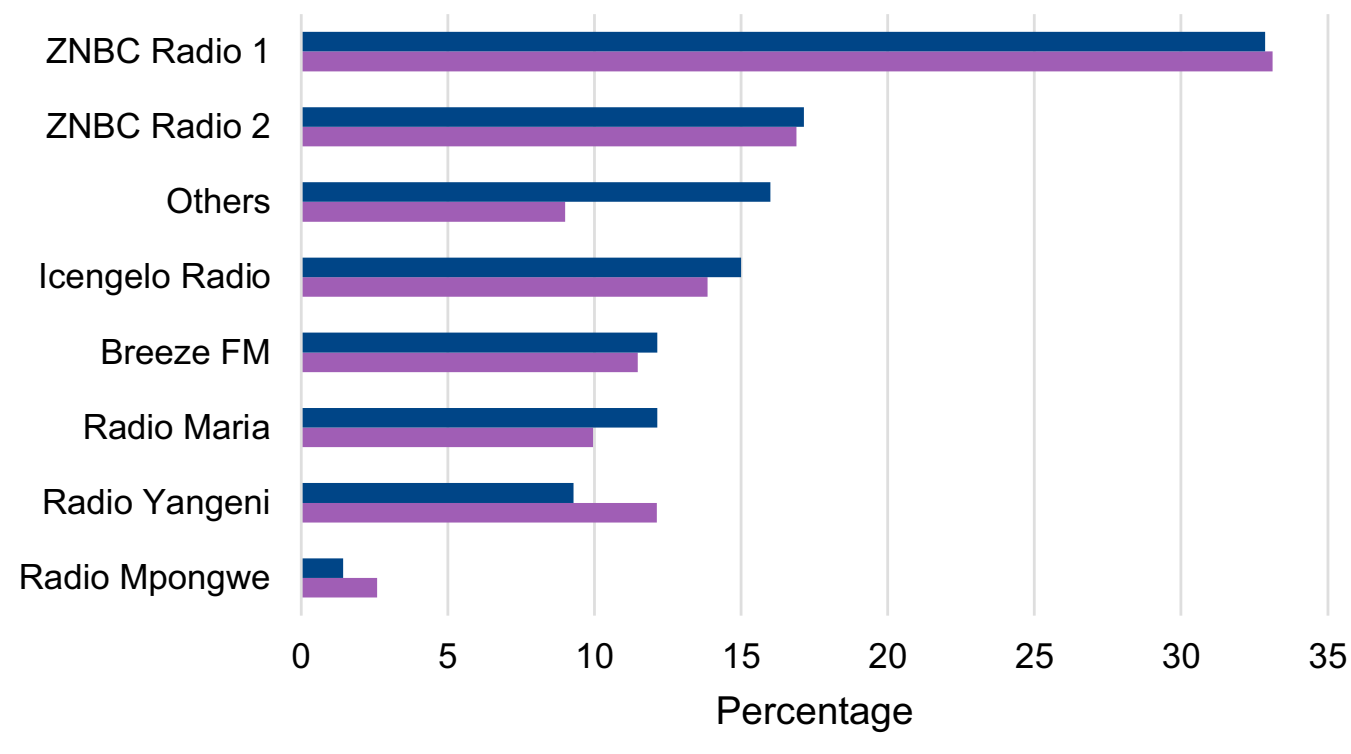

- Non Listerners $\quad$ Listerners

Fig. 3 Comparing radio mostly listened to by both categories 
Table 3 Factors influencing participation in radio campaign

\begin{tabular}{lccc}
\hline Participation in Radio campaign & Coef & Std. Err & P-value \\
\hline Respondent gender (male=1) & 0.14 & 0.044 & $0.002^{* * *}$ \\
Total number of HH members & 0.00 & 0.008 & 0.701 \\
Land under Maize (ha) & 0.03 & 0.017 & $0.055^{*}$ \\
Suffered FAW last season (yes=1) & 0.04 & 0.067 & 0.098 \\
Province: Copperbelt & 0.03 & 0.101 & 0.764 \\
Province: Luampula & -0.24 & 0.096 & $0.019^{* *}$ \\
Province: Eastern & -0.02 & 0.053 & 0.845 \\
Age: between 36 and_60 years & -0.11 & 0.076 & $0.031^{* *}$ \\
Age: Under_35 years & -0.16 & 0.027 & $0.040^{* *}$ \\
Number of HH members working full time on the farm & 0.00 & 0.062 & 0.886 \\
Own mobile phone (1=Yes) & 0.03 & 0.067 \\
Belong to farmers group (1=yes) & 0.11 & 0.026 \\
Education of HH head Primary (1=Yes) & 0.37 & 0.204 & 0.104 \\
Education of HH head Secondary (1=Yes) & 0.10 & 0.168 & $0.074^{*}$ \\
Education of HH head university (1=yes) & 0.04 & 0.104 & 0.563 \\
Constant & 0.14993 & 0.155 & 0.333 \\
\hline
\end{tabular}

***Significant at $1 \%,{ }^{* *}$ significant at $5 \%$ level, * significant at $10 \%$ level

Southern province was set as the base, Age above 60 set as base, and Vocational education as base

$43 \%$ of the non-listeners agreed that crop rotation can help reduce FAW infestation. However, there was no significant difference between the two groups on the statements that FAW can be managed through hand picking and crushing on small scale, where $58 \%$ of both groups agreed. When it came to monitoring, the two groups differed significantly $(\mathrm{p}<0.001)$ on the statement that it is important to visit the maize farm 2-3 weeks after planting and to continue monitoring every 3 days, with $92 \%$ and $75 \%$ of the listeners and non-listeners agreeing, respectively. There was however no significant difference between the two groups on the statement that monitoring FAW is done by walking along edges of maize fields, with $42 \%$ of the listeners and $43 \%$ of the non-listeners agreeing.

\section{Fall armyworm management practices used by farmers}

Campaign messages on management practices included both prevention and direct control. Prevention approaches are aimed at reducing the chances of the pest attacking the field, while control relates to practices to reduce impacts of the pest once already in the field. Results show that both groups of farmers employed different FAW prevention and control practices with radio listeners more likely to adopt management practices than non-radio listeners, particularly preventive measures such as frequent monitoring, intercropping and rotating crops in their fields. Whilst the use of pesticides by radio listeners was higher (Fig. 4). There was no significant difference between radio listeners and non-radio listeners in using biological methods for controlling FAW. This may mean that there is a knowledge gap in Zambia in regard to the use of biological methods in managing FAW infestations. This is an opportunity for both government and development partners to intervene and avail these technologies which are friendlier to human health, environment and are sustainable. Both male and female farmers showed awareness of FAW and implementation of management practices as promoted by the radio campaign albeit with some differences. More male farmers than female were more likely to apply pesticides, while women were more likely to use agronomic and cultural practices than men for the control of FAW. Other studies have also noted differences in practices employed by male and female farmers for FAW management (Kansiime et al. 2019; Tambo et al. 2020), which is largely attributed to differentials in access to resources, inputs and decision making.

Regression results of factors affecting farmer knowledge and management of FAW are shown in Table 5 . The results show that participation in the radio campaign by listening to the radio was positively associated with outcomes on FAW identification, monitoring and management. The result is consistent with previous studies e.g. (Adamides and Stylianou 2018; Tambo et al. 2019), who found that radio contributed significantly to farmers' agricultural knowledge. Hudson et al. (2017) show that the percentage of radio listeners implementing at least one agricultural practice was 2.7 to 2.9 times the percentage of non-listeners in Uganda and Tanzania respectively. 
Table 4 Summary statistics for FAW knowledge questions and scores (\% correct responses)

\begin{tabular}{|c|c|c|c|c|}
\hline Variable (\%) (Correct response $=1$ ) & Overall & Radio listeners & Non-listeners & Sig \\
\hline \multicolumn{5}{|l|}{ Awareness } \\
\hline FAW attacks Only Maize & 33 & 34 & 32 & ns \\
\hline FAW spread through infested seeds & 40 & 36 & 45 & * \\
\hline FAW spread through vegetative materials & 40 & 41 & 38 & ns \\
\hline FAW can cause $100 \%$ damage and loss on Maize & 83 & 86 & 80 & *** \\
\hline FAW attacks all stages of Maize & 83 & 87 & 79 & *** \\
\hline Older FAW caterpillar have Y shaped & 46 & 55 & 38 & ns \\
\hline Signs on FAW damage include small pinholes & 92 & 93 & 91 & *** \\
\hline Heavily infested plants have moist sawdust & 95 & 97 & 92 & *** \\
\hline \multicolumn{5}{|l|}{ Management practices } \\
\hline Hand picking and crushing on small scale & 58 & 58 & 58 & ns \\
\hline FAW can be managed through cultural methods/bio pesticides/chemicals & 64 & 68 & 59 & ns \\
\hline Act to control FAW when $>10$ plants out 50 have signs & 53 & 59 & 47 & * \\
\hline Early planting at the onset of rains can prevent FAW & 82 & 88 & 76 & *** \\
\hline Crop rotation can help reduce FAW & 55 & 68 & 43 & *** \\
\hline Intercropping maize with beans can help reduce FAW & 26 & 33 & 20 & ns \\
\hline Regular weeding of farm can help prevent FAW & 67 & 80 & 55 & *** \\
\hline Pesticides for FAW control are not dangerous for Humans & 81 & 82 & 80 & ns \\
\hline Important to use PPE when mixing or spraying pesticides & 94 & 97 & 90 & *** \\
\hline Empty pesticide containers can be reused & 85 & 89 & 82 & ** \\
\hline Do no spray pesticides when maize is mature or cob drying & 65 & 66 & 64 & ns \\
\hline Mix different pesticides to make them more effective & 65 & 70 & 60 & * \\
\hline \multicolumn{5}{|l|}{ Monitoring } \\
\hline Early FAW detection allow early management & 92 & 94 & 91 & ns \\
\hline Important to visit maize farm 2-3 weeks after planting & 84 & 92 & 75 & *** \\
\hline Important to continue monitoring every 3 days & 88 & 95 & 81 & *** \\
\hline To monitor FAW walk along edges of maize fields & 43 & 42 & 43 & ns \\
\hline To monitor for FAW, examine 50 plants/acre in 5 different locations & 50 & 52 & 48 & ns \\
\hline \multicolumn{5}{|l|}{ Knowledge scores } \\
\hline FAW awareness & 64 & 66 & 61 & ns \\
\hline FAW management practices & 66 & 72 & 61 & ** \\
\hline FAW monitoring & 71 & 75 & 68 & ns \\
\hline Overall FAW knowledge score & 67 & 71 & 63 & * \\
\hline
\end{tabular}

*** Significant at $1 \%,{ }^{* *}$ significant at $5 \%$ level, ${ }^{*}$ significant at $10 \%$ level

This shows that the radio campaign had positive effects in increasing awareness and facilitating farmers' decisions to take up promoted FAW practices.

Household size was positively associated with FAW identification and management, while age of farmer (36 and 60 years) was positively associated with proper FAW identification in comparison to younger or older farmers. This implies that farmers aged between 36 and 60 years were more likely to monitor their maize farms for FAW compared to other age categories. Geographically, farmers in Eastern and Luapula provinces had lower knowledge bases on FAW compared to Southern province. While gender of respondent showed no significant effect on FAW knowledge bases, management practices tended to differ between men and women. Gender of respondent showed no significant influence on FAW awareness, monitoring and management highlight the potential of this approach to enhancing women's participation and access to information.

\section{Conclusion}

This study assessed the effectiveness of radio campaign in achieving scale of farmer reach, and influencing farmer knowledge and practices for FAW management. A multi-stakeholder radio campaign was implemented during the November 2018-April 2019 cropping 


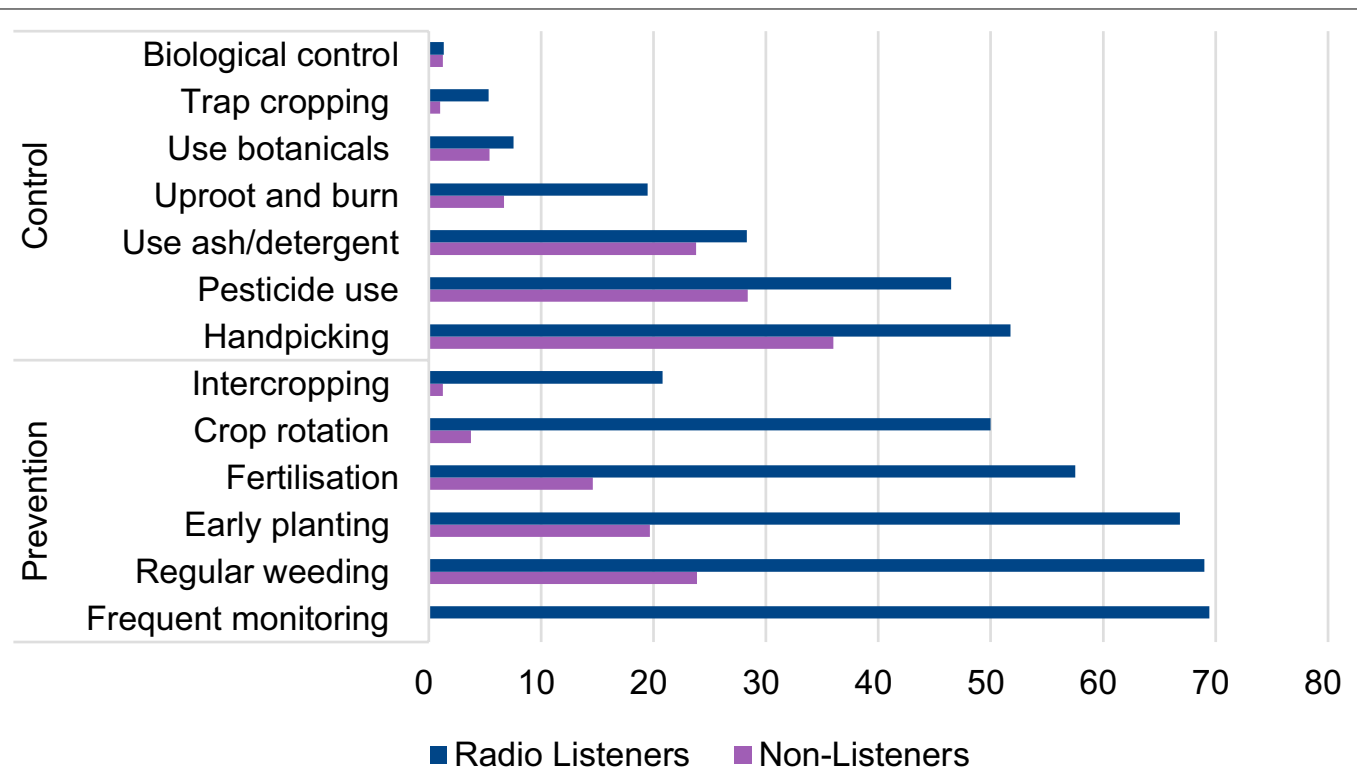

Fig. 4 FAW prevention and control methods between radio listeners and non-radio listeners

Table 5 Factors affecting FAW awareness, monitoring and management

\begin{tabular}{|c|c|c|c|c|c|c|}
\hline \multirow{2}{*}{$\begin{array}{l}\text { Variable } \\
\text { Independent variables }\end{array}$} & \multicolumn{2}{|c|}{ Identification } & \multicolumn{2}{|c|}{ Monitoring } & \multicolumn{2}{|c|}{ Management } \\
\hline & Coef & Std. Err & Coef & Std. Err & Coef & Std. Err \\
\hline Land planted with Maize (ha) & 0.05 & 0.047 & 0.02 & 0.041 & 0.03 & 0.050 \\
\hline Radio listening frequency & 0.02 & 0.053 & -0.07 & 0.046 & -0.03 & 0.056 \\
\hline Respondent gender (male $=1$ ) & 0.13 & 0.125 & 0.02 & 0.109 & 0.11 & 0.132 \\
\hline Total number of $\mathrm{HH}$ members & $0.03^{*}$ & 0.021 & -0.01 & 0.019 & $0.05^{* *}$ & 0.023 \\
\hline Listened to radio $(1=$ Yes $)$ & $0.41^{*}$ & 0.15 & $0.20^{*}$ & 0.130 & $0.74^{* * *}$ & 0.159 \\
\hline Education of HH head Primary (1 = Yes) & -0.4 & 0.289 & -0.08 & 0.251 & -0.07 & 0.306 \\
\hline Education of HH head Secondary ( $1=$ Yes) & -0.27 & 0.298 & -0.16 & 0.259 & 0.10 & 0.315 \\
\hline Education of HH head university (1 = yes) & -0.18 & 0.568 & 0.10 & 0.493 & 0.11 & 0.600 \\
\hline Belong to farmers group ( $1=$ yes) & 0.13 & 0.186 & 0.23 & 0.162 & 0.03 & 0.197 \\
\hline Own mobile phone $(1=$ Yes $)$ & -0.06 & 0.172 & -0.07 & 0.150 & -0.02 & 0.182 \\
\hline Number of HH members working off-farm & 0.09 & 0.074 & 0.06 & 0.064 & $-0.20^{* * *}$ & 0.078 \\
\hline Aged: Under 35 years & 0.3 & 0.212 & $-0.43^{* *}$ & 0.184 & -0.27 & 0.224 \\
\hline Aged between 36 and 60 years & $0.31^{* *}$ & 0.146 & 0.00 & 0.127 & 0.02 & 0.155 \\
\hline Province: Eastern & $-0.81^{* * *}$ & 0.266 & $-0.63^{* * *}$ & 0.231 & $-0.78^{* * *}$ & 0.281 \\
\hline Province: Luapula & -0.27 & 0.283 & $-1.76^{* * *}$ & 0.246 & $-0.97^{* * *}$ & 0.299 \\
\hline Province: Copperbelt & 0.13 & 0.273 & -0.29 & 0.237 & -0.38 & 0.289 \\
\hline Constant & -0.41 & 0.429 & $0.76^{* *}$ & 0.372 & -0.29 & 0.453 \\
\hline
\end{tabular}

*** Significant at $1 \%$ level, ** significant at $5 \%$ level, * Significant at $10 \%$ level

Southern province was set as the base, Age above 60 set as base and Vocational education as base

season, reaching an estimated 1.4 million farmers $(40 \%$ female, and $43 \%$ aged below 35 years) with information on FAW identification, monitoring and management. Partnerships with various stakeholders facilitated knowledge exchange, and provided a useful platform for continued improvement of knowledge related to fall armyworm and further dissemination through other platforms (using the technical brief and the basis).

Survey results showed that both male and female radio listeners were significantly more aware of fall armyworm, 
and more likely to adopt management practices than nonradio listeners, in particular preventive measures such as frequent monitoring, intercropping and crop rotation. This implies that participation in the radio-based extension campaign significantly increased farmers' knowledge and stimulated uptake of management practices for FAW. Radio also achieved a larger reach than would have been possible with face-to-face extension approaches in the same period of time. Thus, utilization of radio can be important in tackling threats of invasive pests like FAW, whose spread is fast, requiring speed and wide coverage of management information.

Gender of respondent showed no significant influence on FAW knowledge base, highlighting the potential of radio in enhancing women's participation and access to information. And consistent with other studies, there were differences in practices used by male and female farmers for the management of FAW, an indication of differences in access to inputs and resources. This implies the need to support access to inputs and technologies alongside provision of information/extension advice.

However, results showed that just about $1 / 2$ of respondents in communities covered by radio were able to listen to at least one radio episode on FAW. Gender of respondent, education level, and maize farm size were significant predictors for farmer participation in radio campaign. This suggests the need to deliberately promote radio programs if listenership is to be enhanced. This can be done through integration of extension approaches including use of ICTs, interactive radio programming, and other inter-personal approaches. The integration of approaches may also be an effective strategy for equally reaching women as men, given the observed digital divide. Interactivity of extension approaches has been found to increase learning and adoption of new practices (Hudson et al. 2017).

\section{Supplementary Information}

The online version contains supplementary material available at https://doi. org/10.1186/s43170-021-00053-8.

Additional file 1. The radio campaign schedule

Additional file 2. Estimation of reach

\section{Acknowledgements}

The study was conducted as part of the Action on Invasive (Aol) program work funded by United Kingdom (Department for International Development), and Netherlands (Directorate-General for International Cooperation). CABI is an international intergovernmental organisation, and gratefully acknowledges the core financial support from our member countries (and lead organisations) including the United Kingdom (Department for International Development), China (Chinese Ministry of Agriculture), Australia (Australian Centre for International Agricultural Research), Canada (Agriculture and Agri-Food Canada), Netherlands (Directorate-General for International Cooperation), and Switzerland (Swiss Agency for Development and Cooperation) and Ireland (Irish Aid, International Fund for Agricultural Development-IFAD). See http:// www.cabi.org/about-cabi/who-we-work-with/key-donors/ for full details. We appreciate key partners who participated in the radio campaigns, monitoring of the campaign and collection of data for this study. Authors are grateful to the farmers, extension officers (key informants), who provided information for this study. We also highly acknowledge the plant doctors who helped to facilitate the study and the enumerators who assisted in data collection.

\section{Authors' contributions}

HR: Data analysis and writing. MKK: supported data cleaning, analysing, interpretation of the data. IM: Paper review and a bit of data analysis. DO: Reviewed the paper to check Campaign context. JAT: Paper review especially on models used. CMB: Logistics in data collection. NAP: Logistics in sata collection and paper review. GC, MM, DC: Paper review country context. TD: Paper review on campaign logic. JG: Paper review gender component. All authors read and approved the final manuscript.

\section{Funding}

The study was conducted as part of the Action on Invasive (Aol) program work funded by United Kingdom (Department for International Development), and Netherlands (Directorate-General for International Cooperation).

\section{Availability of data and materials}

The data that support the findings of this study are available on request from the corresponding author [Harrison Rware]. The data are not publicly available due to [state restrictions e.g." them containing information that could compromise research participant privacy/consent"].

\section{Declarations}

\section{Ethics approval and consent to participate}

This paper is generated using data from an ongoing project on FAW campaign in Zambia. We are using different methods to reach to the farmers with FAW messages and the paper is presenting some of the lessons from the research as approved by the project committee. Roger Day email r.day@cabi.org is the project executive

\section{Consent for publication}

Before collecting the data used in this paper, the identified respondents, (farmers), were asked give their consent of participating in the survey before they were interviewed. They were explained about the survey, purpose and objectives and then a question was paused to them, if they would want to take part and they answered Yes/No.

\section{Competing interests}

The authors declare that they have no competing interests.

\section{Author details}

${ }^{1}$ CABI, Canary Bird, 673 Limuru Road, Muthaiga, P.O. Box 633-00621, Nairobi, Kenya. ${ }^{2} \mathrm{CABI}$, Rue des Grillons 1, 2800 Delémont, Switzerland. ${ }^{3} \mathrm{CABI}$, Lusaka, Zambia. ${ }^{4}$ ZARI, P/B 7, Chilanga, Zambia. ${ }^{5}$ National Agricultural Information Services, Chilanga, Zambia. ${ }^{6} \mathrm{CABI}$, Nosworthy Way, Wallingford OX10 8DE, UK. ${ }^{7} \mathrm{CABI}$, Egham, UK.

Received: 23 October 2020 Accepted: 7 August 2021

Published online: 24 August 2021

\section{References}

Adamides G, Stylianou A. Evaluation of the radio as an agricultural information source in rural areas. J Agric Food Inf. 2018;19(4):362-76. https://doi.org/ 10.1080/10496505.2017.1401480.

Africa Renewal (2005) Community radio: a voice for the poor. Better local communications can boost development, democracy

CABI. Invasive species: the hidden threat to sustainable development. 2018. https://www.invasive-species.org/wp-content/uploads/sites/2/2019/02/ Invasive-Species-The-hidden-threat-to-sustainable-development.pdf.

Chapota, Farm Radio Trust-Malawi. Rapid Assessment on the use of radio in extension advisory services in Mozambique, consultant Report, Submitted to USAID Mozambique. 2015. 
Duncombe R. Mobile phones for agricultural and rural development: a literature review and future research directions. 2012. https://humme dia.manchester.ac.uk/institutes/gdi/publications/workingpapers/di/di_ wp50.pdf.

Emily B, Mark BN, G Rutamu. Extension \& advisory services in Zambia: understanding structures, services, roles \& incentives for reaching farmer households as a basis for discussing potential for scale. United States Agency for International Development (USAID) and US Government Feed the Future project "Integrating Gender and Nutrition within Extension and Advisory Services" (INGENAES), Leader with Associates Cooperative Agreement No. AID-OAA-LA-14-00008. 2017. www.ingenaes.illinois.edu.

Emmanuel AA, Olabode BI. Listenership of radio agricultural broadcasts in southwestern Nigeria. J Appl Environ Educ Commun. 2013;2013(11):3-4.

FAO. Integrated management of the Fall Armyworm on maize. A guide for Farmer Field Schools in Africa. Rome: FAO; 2018.

Hailu G, Pittchar JO, Khan ZR, Ochatum N. Perceived preference of radio as agricultural information source among smallholder farmers in Uganda. International Center of Insect Physiology and Ecology (icipe), Uganda. 2017. https://esciencepress.net/journals/index.php/IJAE/article/view/ 2318

Hudson HE, Leclair M, Pelletier B, Sullivan B. Using radio and interactive ICTs to improve food security among smallholder farmers in Sub-Saharan Africa. Telecommun Policy. 2017. https://doi.org/10.1016/j.telpol.2017.05.010.

IAPRI, 2016. Fall Armyworm Outbreak in Zambia : Lessons Learnt To Avert Futur.e Outbreaks.

Information and Communications Technology Authority (ZICTA). 2018. Kansiime KM, Mugambi I, Rwomushana I, Nunda W, Lamontagne-Godwin J, Rware H, Phiri NA, Chipabika G, Ndlovu M, Day R. Farmer perception of fall armyworm (Spodoptera frugiderda J.E. Smith) and farm-level management practices in Zambia. Pest Manag Sci. 2019. https://doi.org/ $10.1002 / p s .5504$.

Kembero MMR. The Role of Radio in Agricultural Development: An Evaluation of the Programme Oboremi Bwaito on Egesa FM in Bomachoge Chache Constituency [Research project]. Submitted to the school of journalism and mass communication in partial fulfilment of the requirements for the award of degree of master of arts in communication studies, University of NairobiKembero, 2014.

Masuki KF, Tukahirwa J, Kamugisha R, Mowo J, Tanui J, Mogoi J Adera EO. Mobile phones in agricultural information delivery for rural development in Eastern Africa: Lessons from Western Uganda. 2010. http://apps.world agroforestry.org/downloads/Publications/PDFS/MM10320.pdf.

Pratt CF, Constantine KL, Murphy ST. Economic impacts of invasive alien species on African smallholder livelihoods. Glob Food Sec. 2017. https://doi. org/10.1016/j.gfs.2017.01.011.

Rwomushana I, Bateman M, Beale T, Beseh P, Cameron K, Chiluba M, Clottey V, Davis T, Day R, Early R, Godwin J, Gonzalez-Moreno P, Kansiime M, Kenis M, Makale F, Mugambi I, Murphy S, Nunda W, Phiri N, Pratt C, Tambo J. Fall armyworm: Impacts and implication for Africa. CAB International. https:// www.invasive-species.org/wp-content/uploads/sites/2/2019/02/FAWEvidence-Note-October-2018.pdf 2012.

Staatz JM, Dembélé NN. 2008. Agriculture for Development in Sub-Saharan Africa Agriculture for Development in Sub-Saharan Africa Background Paper for WDR 2008.

Tambo JA, Aliamo C, Davis T, Mugambi I, Romney D, Onyango DO, Kansiime M, Alokit C, Byantwale ST. The impact of ICT-enabled extension campaign on farmers' knowledge and management of fall armyworm in Uganda. PLoS ONE. 2019;14(8): e0220844. https://doi.org/10.1371/journal.pone. 0220844

Tambo JA, Kansiime MK, Mugambi I, Rwomushana I, Kenis M, Day RK, Lamontagne-Godwin J. Understanding smallholders'responses to fall armyworm (Spodoptera frugiperda) invasion: Evidence from five African countries. Sci Total Environ. 2020;740:140015. https://doi.org/10.1016/j. scitotenv.2020.140015.

Wanyama R, Mathenge M, Mbaka Z. Agricultural Information Sources and their Effect on Farm productivity in Kenya. 2015

\section{Publisher's Note}

Springer Nature remains neutral with regard to jurisdictional claims in published maps and institutional affiliations.
Ready to submit your research? Choose BMC and benefit from:

- fast, convenient online submission

- thorough peer review by experienced researchers in your field

- rapid publication on acceptance

- support for research data, including large and complex data types

- gold Open Access which fosters wider collaboration and increased citations

- maximum visibility for your research: over $100 \mathrm{M}$ website views per year

At BMC, research is always in progress.

Learn more biomedcentral.com/submissions 